\title{
THERMAL COMFORT AND ENERGY CONSUMPTION USING DIFFERENT RADIANT HEATING/COOLING SYSTEMS IN A MODERN OFFICE BUILDING
}

Ema Nemethova ${ }^{1 *}$, Werner Stutterecker ${ }^{2}$, Thomas Schoberer ${ }^{3}$

\section{Abstract}

The aim of the study is to evaluate the potential of enhancing thermal comfort and energy consumption created by three different radiant systems in the newly-built Energetikum office building. A representative office, Simulation room 1/1, was selected from 6 areas equipped with portable sensor groups for the indoor environment monitoring. The presented data obtained from 3 reference weeks; the heating, transition and cooling periods indicate overheating, particularly during the heating and transition period. The values of the indoor air temperature during the heating and transition period could not meet the normative criteria according to standard EN 15251:2007 (cat. II.) for 15-30\% of the time intervals evaluated. Consequently, a simulation model of the selected office was created and points to the possibilities of improving the control system, which can lead to an elimination of the problem with overheating. Three different radiant systems - floor heating/ cooling, a thermally active ceiling, and a near-surface thermally active ceiling were implemented in the model. A comparison of their effects on thermal comfort and energy consumption is presented in the paper.

\section{Address}

1 Slovak University of Technology in Bratislava, Department of Building Services, Radlinskeho 11, 81005 Bratislava, Slovak Republic

2 Fachhochschule Burgenland GmbH, Department of Energy and Environmental Management, Steinamangerstraße 21, A-7423 Pinkafeld, Austria

3 Forschung Burgenland GmbH, Steinamangerstraße 21, A-7423 Pinkafeld, Austria

* Corresponding author: nemethova.ema@gmail.com

Key words

- Thermal comfort

- Glazed envelope,

- Overheating

- Simulation.

\section{INTRODUCTION}

Environmental comfort in offices ought to provide optimal conditions for the efficient productivity of the occupants. However, a recent trend in construction, i.e., light-weight facades with a high portion of glazed components in combination with radiant heating/ cooling systems, reveals extensive thermal comfort issues. With regard to the fact that lightweight glazed facades are very sensitive to climatic conditions, a properly designed combination of HVAC, lightning, and solar shading set-points is crucial for energy performance. The research is focused on the environmental behaviour of a newly-built office building, particularly on a problem with thermal discomfort.

\section{A MODERN OFFICE BUILDING WITH LARGE GLAZED AREAS}

Large glazed areas are always related to higher energy losses during the heating season and to the overheating of indoor spaces because of the direct sun (Brunner et. al, 2001). During the summer problems with interior overheating are expected; however, cold days with a high amount of solar irradiation, when the solar gains exceed the energy demands for the heating, are a crucial area of HVAC design. This problem is very significant in buildings with a centralised heating and ventilation system, where some parts of the buildings should be heated and some cooled at the same time. However, to protect the building from unwanted solar gains (by an automatically 
controlled shading system), a compromise between the day lighting and solar gains has to be achieved.

Research on people's performance while working under different thermal conditions showed results indicating lower performance during uncomfortable air temperature periods (Šeduikyte and Paukštys, 2008). According to (Niemmela et. al, 2002), employees' performance decreased by $2.2 \%$ by every $1{ }^{\circ} \mathrm{C}$ over $25{ }^{\circ} \mathrm{C}$. Other research in an office building showed a decrease in performance of $15 \%$ when the temperature increased from $24.8{ }^{\circ} \mathrm{C}$ to $26^{\circ} \mathrm{C}$ (Federspiel et. al, 2002).

As there is indisputable pressure on the energy efficiency of buildings, low-exergy radiant systems are being implemented in building technology. Radiant heating systems are very suitable combined with renewable energy sources, e.g., heat pumps and solar collectors. The external weather conditions, solar irradiance, changes in internal heat gains, and the small heat accumulation capability of a light-weight facade can result in relatively dynamic changes in the thermal balance of a building. Due to the high time constant, i.e., the slow reactions of radiant heating/cooling systems, it may not be able to respond to these changes fast enough to assure a comfortable thermal environment, which can lead in naturally ventilated buildings to temperatures as high as $29.5^{\circ} \mathrm{C}$ (Nemethova et. al, 2016a).

\section{DESCRIPTION OF THE REFERENCE OBJECT AND ZONE}

Due to the lack of suitable currently constructed experimental buildings, an interdisciplinary living laboratory, the Energetikum, was designed. An investigation of an indoor environment as a result of a properly designed control of HVAC systems and other building technology, was one of the main purposes of the project. Simulation room $1 / 1$, which is located in the building, has been used as an office for the employees of Research Burgenland GmbH since April 2015.

\subsection{Building envelope, construction and thermal properties}

The two-storey building, which is located in Pinkafeld, Austria, has two types of façade to eliminate higher heating demands during the winter and provide the best conditions for the infiltration of natural lighting. Opaque surfaces constitute 82 percent of the envelope, and the light-weight components or windows constitute 18 percent (orientated to the W-S-W and S-S-E). All the transparent parts of the façade have a triple glazing with a thermal transmittance value between 0.79 and $1.10 \mathrm{~W} /\left(\mathrm{m}^{2} . \mathrm{K}\right)$. The Simulation Room, with its fully glazed envelope oriented to the west-south-west, is located on the second floor of the building. The office, with a floor area of $26.4 \mathrm{~m}^{2}$, is regularly occupied by 2 employees.

\subsection{Description of the HVAC systems installed}

A brine/water heat pump was installed to supply the whole Energetikum structure with heat. The area available for geothermal energy is too low to cover the power supply created by the heat pump. Therefore, an additional energy source, a gas boiler, was installed. Three separate distribution systems have been implemented for the heating/cooling system (Fig. 1). The systems can run simultaneously or separately, depending on the current demands. The structure is mechanically ventilated and provides complex air conditioning. The air exchange is fully covered by mechanical ventilation; the window openings are not essential to maintain the minimal air change rates.

Ext.

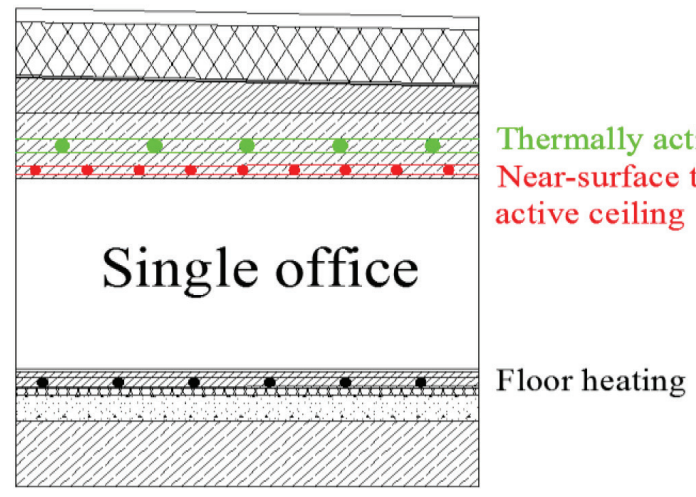

Fig. 1 Heating and cooling systems - Simulation room 1/1

\section{ASSESSMENT OF THERMAL COMFORT AND DETERMINATION OF THE CRITICAL AREAS}

For monitoring the various indoor environmental indicators such as the air temperature, relative humidity, and concentration of carbon dioxide, portable sensor groups were installed in six selected offices in 2016. Energy consumption sensors, sensors measuring the heating and ventilation system properties, and a weather station measuring the ambient conditions were simultaneously installed. Based on the recorded data, it is possible to evaluate the indoor environmental quality, energy consumption, and behaviour of the HVAC systems.

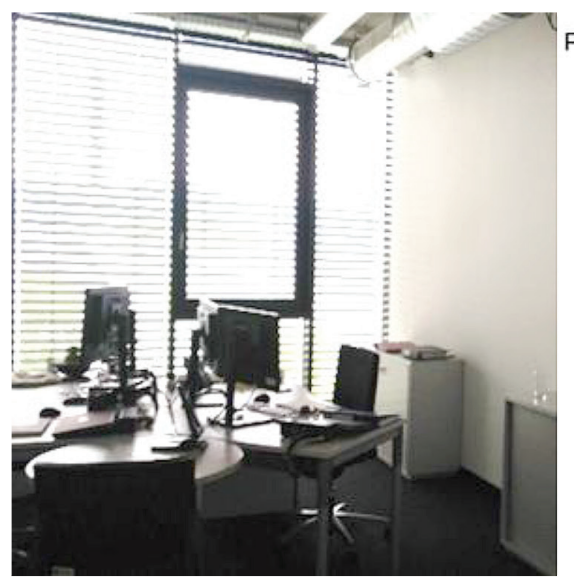

PORTABLE FH SENSOR GROUPS - WSN-3226
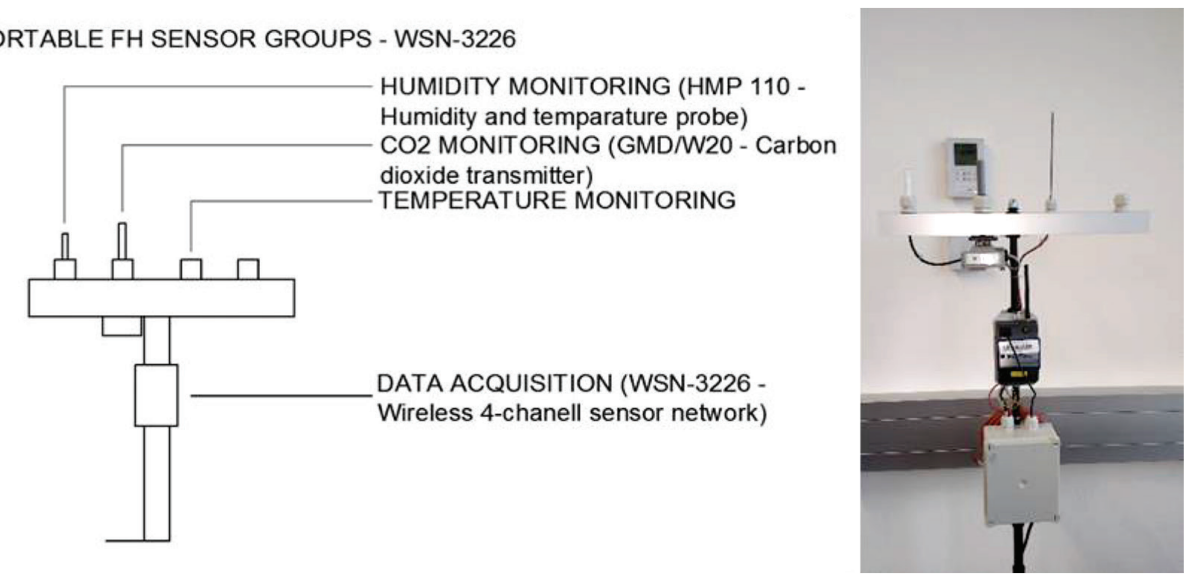

Fig. 2 Portable monitoring technology - Simulation room 1/1 


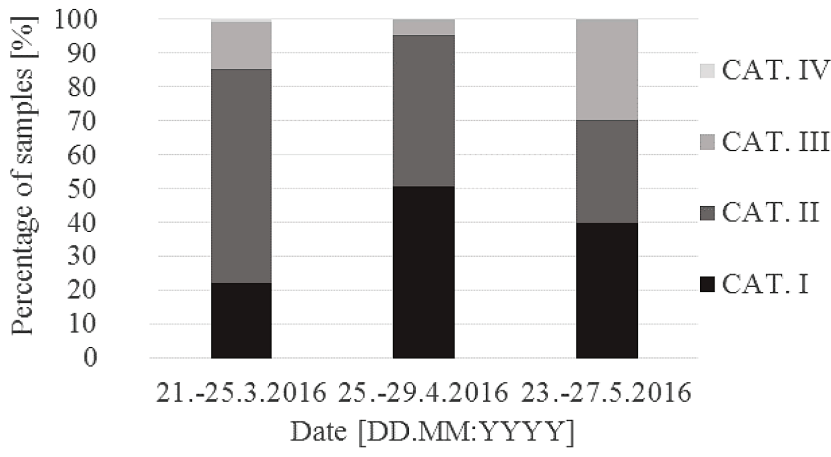

Fig. 3 Classification of thermal environment into 4 categories in accordance with EN 15251 - Simulation Room 1/1

\subsection{Monitoring the thermal comfort and technology installed}

Besides the pre-installed SIEMENS sensors, which are aimed at the HVAC operation and control, portable "monitoring-trees" with highly sensitive sensors were installed. These help to detect problems with the indoor environment and energy consumption. There is a potential for energy-saving improvements via applications of different control strategies to the system.

\subsection{Results and observations}

Time samples were collected during three reference weeks during year (2016), and the data was sorted according to the working hours (6:00 AM - 6:00 PM) and assessed in accordance with EN 15251:2007.

According to EN 15251, the room can be classified in one of four indoor environment categories. The nominal level of expectations for new and renovated buildings is represented by category II $\left(20-24{ }^{\circ} \mathrm{C}\right.$ for heating, $23-26{ }^{\circ} \mathrm{C}$ for cooling). The results of the air temperature and classification in the four categories of thermal comfort are shown in Fig. 3. Category IV can be tolerated for only a very limited time period. The results indicate that the desired thermal environment was achieved for only a limited period of time, which was mostly due to the excessive air temperature. According to Fig. 3, the thermal environment in the building suffers from thermal discomfort during all three periods. Overheating mainly occurs in the transition and heating period; during the cooling period, the discomfort is mainly caused by temperatures below the values required by the standard.

The temperature curves in Fig. 4 represent the amplitudes of the indoor air temperature in the reference offices. Generally, the temperature range is above the desired range during the heating period and below the desired area during the cooling period, which suggests that the control system is not considering an adaptive principle. By adjusting the set temperatures or control settings (e.g., the PI controller, shading devices, flow rates), it would be possible to save a significant amount of energy simultaneously while enhancing the thermal comfort.

The peak of overheating occurs during the afternoon, as a consequence of the solar gain accumulation and low heat losses. However, as the automatic shading system was not operating during the time periods evaluated, the behaviour of the occupants strongly influenced the thermal conditions in the corresponding offices (opening windows, the shading control). With regard to the fact that the building is still in a trial operation, the building's operation is being observed to find the most suitable solutions for the issues raised. Consequently,

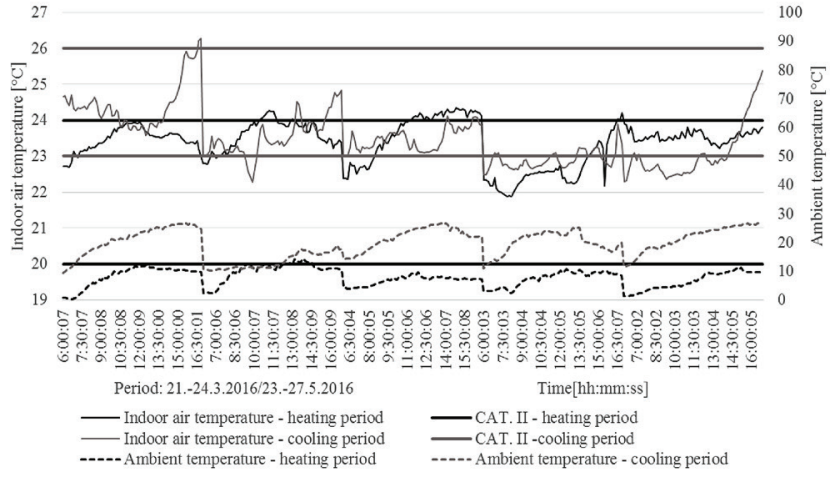

Fig. 4 Comparison of indoor air temperatures in the reference office during the occupied time intervals of the 3 periods evaluated

different control strategies for the HVAC systems should be considered, which will create a challenge for further study and research.

\section{SIMULATION OF BUILDING PERFORMANCE - ENERGY CONSUMPTION AND THERMAL COMFORT}

As a tool for examining the possibility of reducing the overheating, the simulation of a reference room located in the structure was undertaken. Simulation room 1 was selected because of its orientation and because a portion of the glazed areas was convenient for the experiment. As the problem with the thermal comfort during the cooling period (temperatures lower than that required by the standards), which is caused by the low set-point temperatures of the cooling system, can be quite easily reduced, the reference week from the heating period was chosen for the study. The model presented was developed within a TRNSYS environment.

\subsection{HVAC systems control and set-points}

A system of radiant floor heating with a stable flow rate of 190 1/h was implemented in the model to cover the heat demand of the zone. The inlet temperature was maintained at the desired value by a threeway mixing valve. A PI controlling algorithm was applied to minimize the temperature fluctuations at around $21{ }^{\circ} \mathrm{C}$ during the occupied time periods and $16{ }^{\circ} \mathrm{C}$ during the night by adjusting the inlet flow rate temperature of the radiant heating.

Normative air change $4[1 / \mathrm{h}]$ is provided by the ventilation system. The inlet air temperature varies and ranges between $17^{\circ} \mathrm{C}$ and $22{ }^{\circ} \mathrm{C}$. The air change rate is controlled by a three stage controller, depending on the $\mathrm{CO}_{2}$ concentration of the indoor air. The temperature of the inlet is controlled proportionally, depending on the amount of solar radiation.

A system of blinds with $80 \%$ impenetrability protects the room from any redundant solar gains. The room occupation, lightning system, and installed equipment are also integrated into the model.

Four set-point variations were selected to examine the effect of the shading and ventilation system on the thermal comfort (Tab. 1). The position of the blinds was assigned according to the amount of incident solar radiation on the external wall. An excessive solar radiation value of $600 \mathrm{~kJ} / \mathrm{h} . \mathrm{m}^{2}$ causes the blinds to fully cover the window, which results in a reflection of $80 \%$ of the solar radiation. Otherwise, the shading covers $30 \%$ of the window area. The ventilation system is set to a temperature of $21{ }^{\circ} \mathrm{C}$. However, when the blinds system is not capable of covering the solar radiation, the tem- 
perature can be proportionally lowered to $17{ }^{\circ} \mathrm{C}$. During the night, the temperatures and air change rates decrease, according to the night setback (Nemethova et. al, 2016b).

Tab. 1 Set-point comparison - 4 variations

\begin{tabular}{|l|c|c|c|c|}
\hline & Variation 1 & Variation 2 & Variation 3 & Variation 4 \\
\hline $\begin{array}{l}\text { Shading system } \\
\text { operation }\end{array}$ & $\begin{array}{c}\text { On } \\
(30 / 100 \%)\end{array}$ & Off & $\begin{array}{c}\text { On } \\
(30 / 100 \%)\end{array}$ & Off \\
\hline $\begin{array}{l}\text { Ventilation inlet } \\
\text { temperatures }\end{array}$ & $17-22^{\circ} \mathrm{C}$ & $17-22^{\circ} \mathrm{C}$ & $22^{\circ} \mathrm{C}$ & $22^{\circ} \mathrm{C}$ \\
\hline
\end{tabular}

The indoor air temperature and the corresponding values of the solar radiation during the heating period are shown in Fig. 5. During the first simulated day with a low level of solar radiation, the indoor air temperature was at about the same level for all the variants, regardless of whether the blinds are fully open or closed. This is in agreement with the results of the physical measurements during overcast days. However, during the subsequent simulated days with higher solar radiation, the indoor air temperature rapidly changed, and the difference in temperature between variants V1 and V2 reached over $5{ }^{\circ} \mathrm{C}$. These results indicate the important effect of automation and shading control on the thermal balance of the building. When the blinds were not in operation, the air temperature in variants V2 and V4 exceeded $26{ }^{\circ} \mathrm{C}$ even during days with an ambient temperature below $10{ }^{\circ} \mathrm{C}$, which causes thermal discomfort. The least favourable results were obtained for variant V4, when the blinds were not in operation, and the inlet air temperature was kept constant at $22{ }^{\circ} \mathrm{C}$; in this case the thermal comfort was outside category II around $26 \%$ of the time. In variant V2 the negative effect of any excessive solar gains is partially counterbalanced by the cooling effect of the cold ventilated air. The results of the indoor air temperature are most favourable for variants $\mathrm{V} 1$ and V3 when the blinds are in operation; in this case the room air temperature during the occupied hours is always kept near the desired $22{ }^{\circ} \mathrm{C}$, and the thermal comfort is within category II more than $90 \%$ of the time. The best results were achieved for variant V1, when the blinds are in operation, and the inlet air temperature is allowed to drop down to $17{ }^{\circ} \mathrm{C}$ when needed (Nemethova et. al, 2016b).

\subsection{Comparison of the three radiant systems}

The simulations were performed for the three heat/cool emission systems (a thermally active core with pipes embedded in the middle of a concrete ceiling, a thermally active core with pipes embedded near the ceiling's surface, and floor heating) installed in the building to investigate the effect of different emission systems on thermal comfort (Tab. 2). The control strategies and set points described in variant V1 (Tab. 1) were used for this comparison.

The parameters of operation for the three simulated radiant systems shown in Fig. 6 and the indoor air temperatures shown in Fig. 7 indicate that the inlet temperature, pump operation cycles, and thermal environment are very similar for all three emission systems.

Thus, for the most favourable variant V1, all the simulated emission systems are capable of creating a comfortable thermal environment despite the high thermal inertia of the accumulated concrete

Tab. 2 Parameters of the three radiant systems

\begin{tabular}{|l|c|c|c|c|}
\hline Radiant system type & Effective area $\left[\mathrm{m}^{2}\right]$ & Volume flow rate $[\mathrm{l} / \mathrm{h}]$ & Pipe spacing $[\mathrm{mm}]$ & Pipe dimension [mm] \\
\hline Floor heating / cooling & 26.5 & 190 & 150 & $16 \times 1.8$ \\
\hline Thermally active ceiling & 20 & 280 & 150 & $20 \times 2.3$ \\
\hline Near-surface thermally active ceiling & 14 & 270 & 100 & $14 \times 2.0$ \\
\hline
\end{tabular}

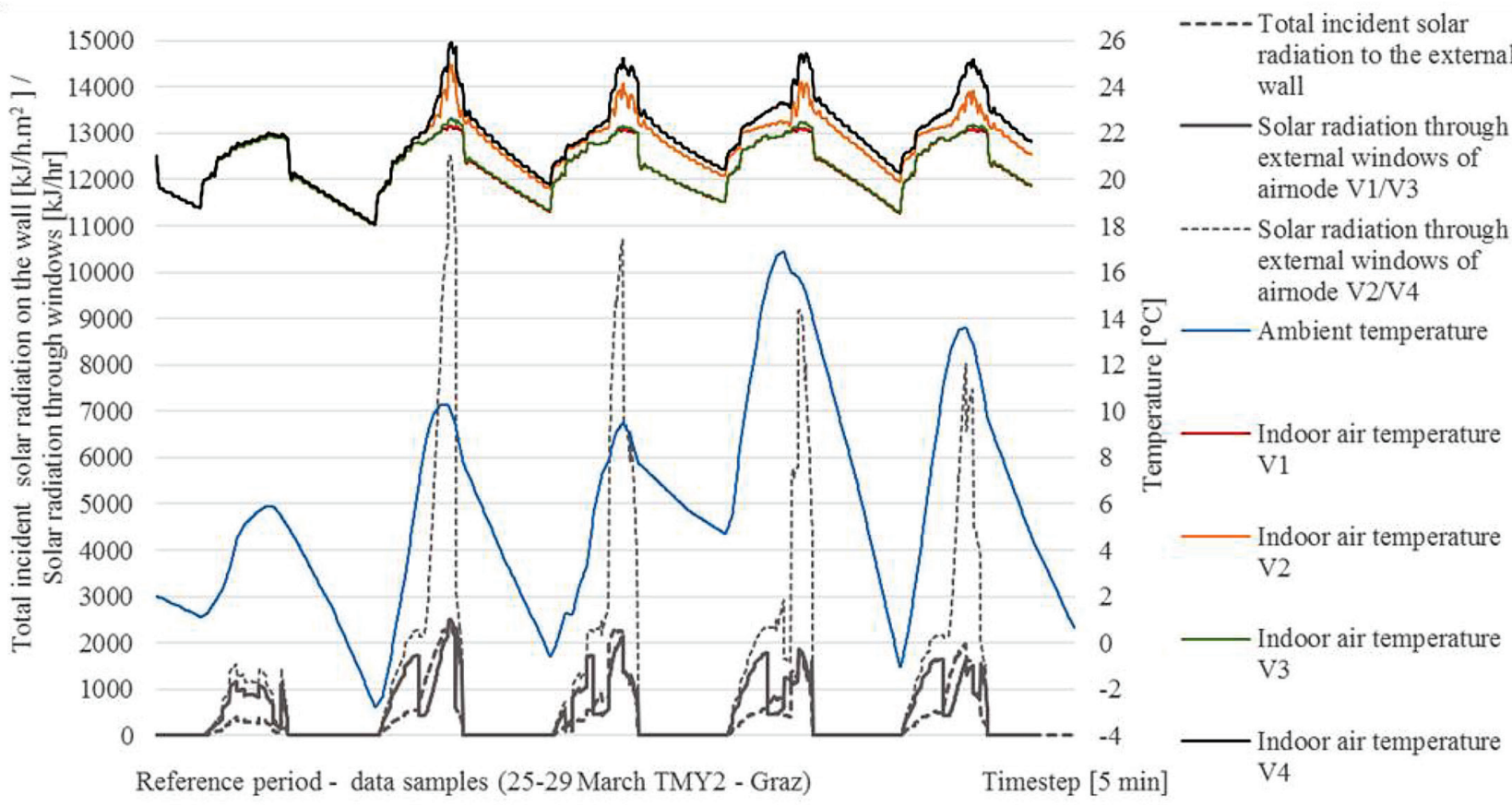

Fig. 5 TRNSYS output - indoor air temperatures and solar radiation profiles (four set-point variants) while using the floor heating system, ventilation and shading 


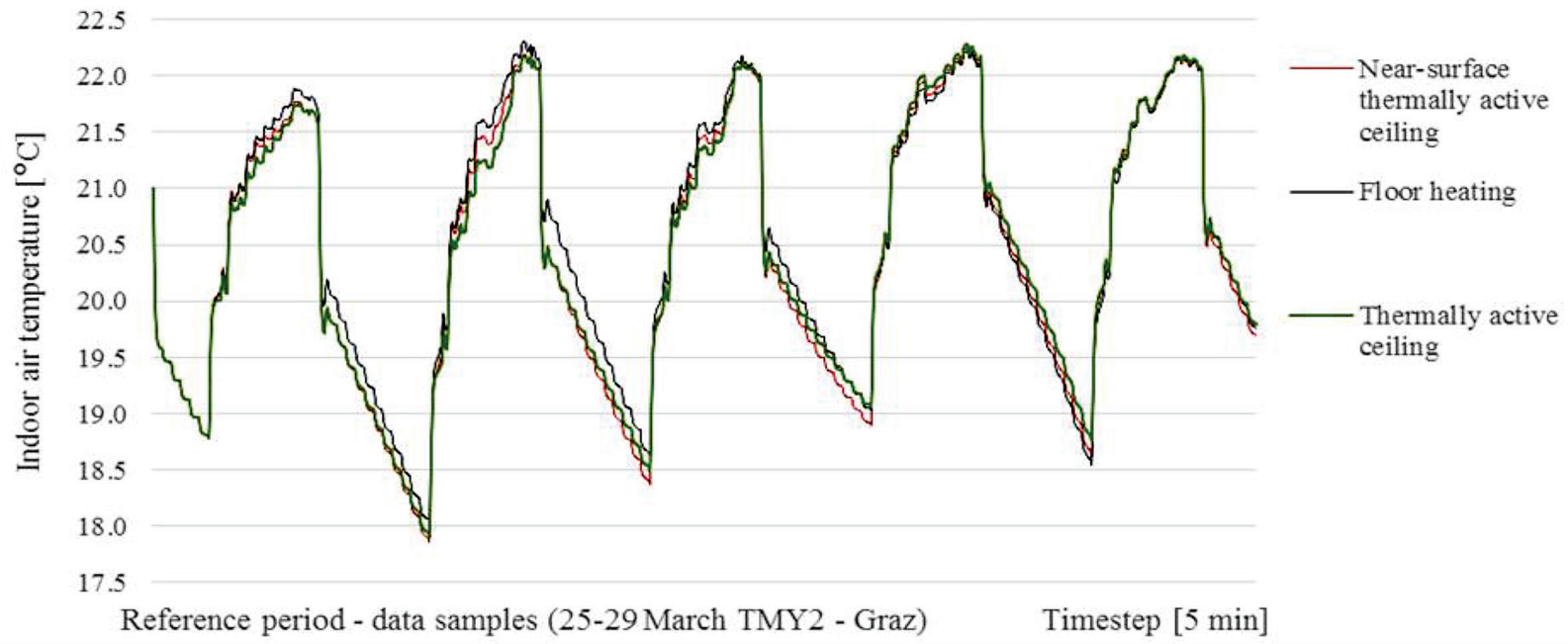

Fig. 6 TRNSYS output - comparison of indoor air temperatures created by the three simulated radiant systems

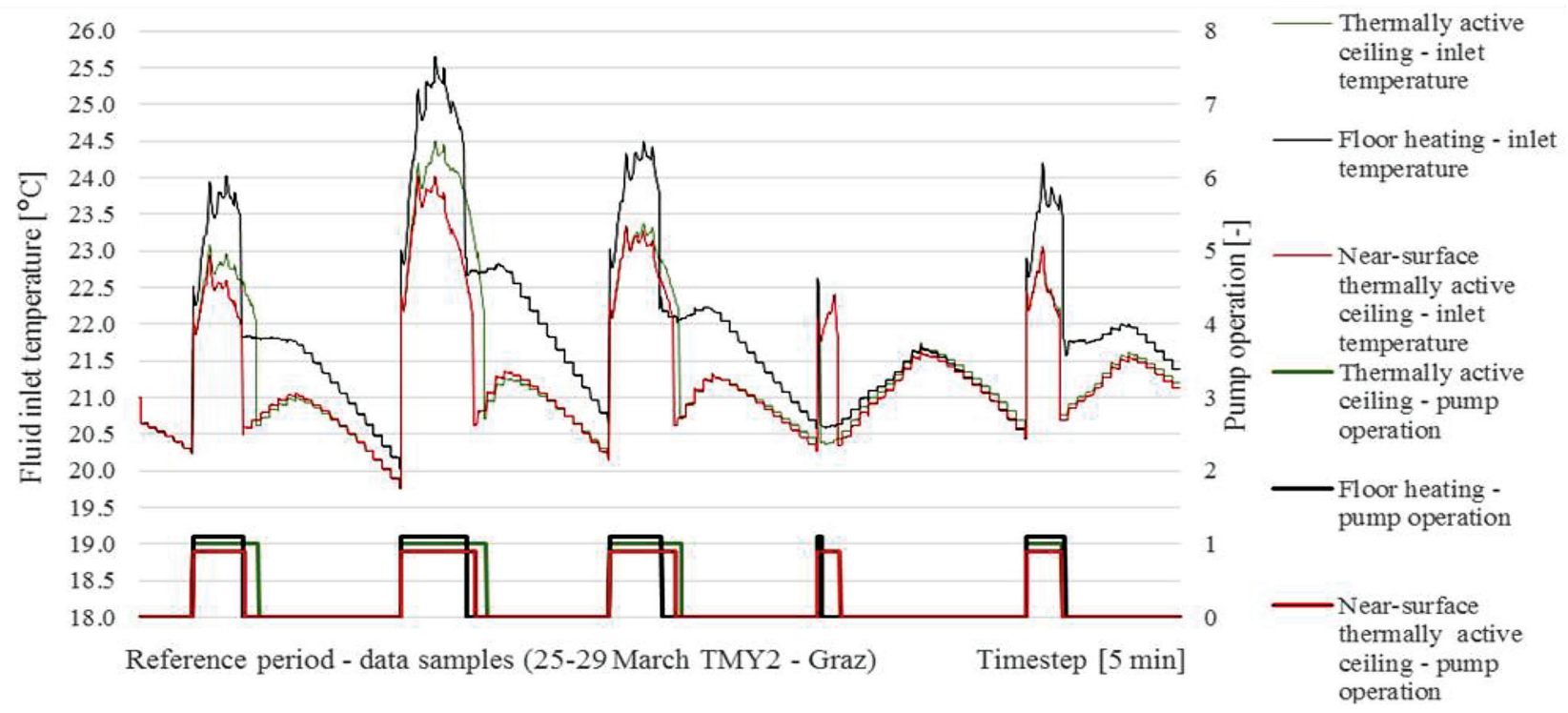

Fig. 7 TRNSYS output - operation parameters of the three simulated radiant systems

core. The energy consumption was almost identical for the floor heating and the near-surface thermally active ceiling, whereas it was $23 \%$ higher for the thermally active ceiling with pipes in the middle of the concrete core than for the other two systems.

\section{CONCLUSION}

The physical measurements revealed problems with thermal discomfort due to overheating in the heating period and overcooling in the cooling period. The problems with overcooling can be solved by properly adjusting the room's air set-point temperature. The uncomfortably high room air temperature in the winter was caused by excessive solar heat gains through the large glazed areas of the façade, and also partially by the slow reaction of the emission systems with the high accumulation capacity for changes in the thermal balance. The computer simulations indicate that the problems can be eliminated and that a comfortable thermal environment can be created in the winter by: a) a proper control strategy of the heating system with high thermal inertia, b) a proper automated control of the external blinds and ventilation temperature. The enhanced blinds and inlet air temperature control led to about a $20 \%$ reduction of the time outside the recommended limit as compared to the alternative with no blinds and a constant inlet air temperature. However, the influence of the radiant heating / cooling system type is negligible in comparison with the proper control setting of the system.

\section{Acknowledgment}

The authors want to thank all their supporters: VEGA project 1/0807/17, Danube Strategy project DS-2016-0030, project energy4buildings funded by the Austrian Federal Ministry for Transport, Innovation and Technology BMVIT and the Austrian Federal Ministry of Science, Research and Economy BMWFW within the COIN funding scheme. The Energetikum living lab was funded by the European Regional Development Fund and the Government of Burgenland, Austria. 


\section{REFERENCES}

Brunner, C. - Baumgartner, T.- Bruhwiler - D., Schneiter - T.F. Steineman, U. (2001) Highly Glazed Buildings - Comfort and Energy Efficiency. SIA (Swiss Society for Engineers and Architects), D 0176, Switzerland.

Šeduikyte, L. - Paukštys, V. (2008) Evaluation of indoor environment conditions in offices located in buildings with large glazed areas. In: Journal of Civil Engineering and Management 14:1, pp. 39-44.

Niemela, R. - Hannula, M. - Rautio, S. - Reijuka, K. - Railio, J. (2002)

The effect of indoor air temperature on labour productivity in call centres - a case study. In: Energy and Buildings 34, pp. 759-764.

Federspiel, C. - Liu, G. - Lahiff, M. (2002)

Worker performance and ventilation: analyses of individual data for call-centre workers. IN: Proc. of Indoor Air 2002, 9th International Conference on Indoor Air Quality and Climate. Monterey, CA, USA, pp. 796-801.

Nemethova, E. - Petras, D. - Krajcik, M. (2016a)

Indoor environment in a high-rise building with lightweight envelope and thermally active ceiling. In: CLIMA 2016: Proceedings of the 12th REHVA World Congress. Aalborg, Denmark, 22.-25.5.2016. Aalborg: Aalborg University, online.

Némethová, E. - Petráš, D. - Stutterecker, W. - Schoberer, T. (2016b)

Indoor environment challenges in a new type office building - case study. In E-NOVA 2016 : Internationaler Kongress. Nachhaltige Technologien. Pinkafeld, Österreich, 24. und 25. November 2016. Graz: Leykam Buchverlagsgesellschaft, pp. 177-187. 